\title{
Transformasi Lingkungan Pembelajaran Berbasis Literasi Digital Pada Anak Usia Dini
}

\section{Mulyana Sukarnih Putri ${ }^{*}$, Chairiyah2}

1,2 Prodi Pendidikan Guru Pendidikan Anak Usia Dini, Universitas Pendidikan Ganesha, Singaraja, Indonesia

\section{ART I CLE I N F O}

\section{Article history:}

Received August 14, 2021

Revised August 15, 2021

Accepted November 10, 2021

Available online December 25, 2021

Kata Kunci:

Lingkungan Pembelajaran, Literasi

Digital, Pembelajaran Online

Keywords:

Learning Environment, Digital

Literacy, Online Learning

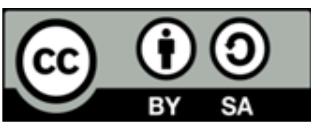

This is an open access article under the CC BY-SA license.

Copyright (c) 2021 by Author. Published by Universitas Pendidikan Ganesha.

\begin{abstract}
A B S T R A K
Kekhawatiran guru untuk meminimalkan resiko bahaya online pada anak usia dini. Selain itu, peran orang tua yang masih belum maksimal dalam pendampingan belajar virtual anak dalam penggunaan internet yang bemakna. Tujuan penelitian untuk menganalisis sejauhmana kemampuan anak usia dini dalam beradaptasi dengan lingkungan pembelajaran berbasis literasi digital. Metodologi penelitian yang digunakan kualitatif deskriptif, metode pengambilan data dengan observasi dan wawancara dengan pedoman pada tiga aspek penting pengukuran, yaitu: dukungan media sosial, kondisi jaringan atau akses, dan peningkatan hasil akademik selama anak belajar online. Subjek penelitian diambil secara random sampling, yaitu: empat orang tua siswa. Analisis data dilakukan dengan triangulasi sumber data untuk menggali kebenaran infromasi tertentu. Sedangkan desain penelitian berdasarkan pendekatan Miles dan Hubermen, yaitu: reduksi data, penyajian data, dan penarikan kesimpulan/verifikasi. Hasil menunjukkan bahwa literasi digital masih belum banyak di bahas dan penting untuk ditanamkan pada anak usia dini, memperkenalkan bagaimana transformasi lingkungan pembelajaran pada masa pandemic saat ini. Beralih dari lingkungan tatap muka di kelas menjadi lingkungan pembelajaran online. Melalui dukungan media sosial, guru dapat memvariasikan pembelajaran untuk menarik perhatian anak PAUD. Selain akses jaringan yang mempengaruhi, guru dan orang tua termasuk komponen penting agar anak terawasi sehingga tidak menyalahgunakan dalam pembelajaran online. Dukungan guru dan orang tua, serta akses dalam menunjang transformasi lingkungan pembelajaran berbasis literasi digital sebagai alternatif baru yang dapat pula meningkatkan hasil akademik siswa melalui lingkungan pembelajaran online.
\end{abstract}

\begin{abstract}
A B S T R A C T
The teacher's concern is to minimize the risk of online harm in early childhood. In addition, the role of parents is still not optimal in assisting children's virtual learning in meaningful use of the internet. The purpose of this research is to analyze the extent to which early childhood is capable of adapting to a digital literacy-based learning environment. The research methodology used is descriptive qualitative data collection method by observation and interviews with guidelines on three critical aspects of measurement: social media support, network conditions or access, and improving academic results while children study online. The research subjects were taken by random sampling: four students' parents. Data analysis was carried out by triangulating data sources to explore the truth of certain information. While the research design is based on the Miles and Huberman approach, namely: data reduction, data presentation, and concluding/verification. The results show that digital literacy has not been widely discussed and is essential to instill in early childhood, introducing how to transform the learning environment during the current pandemic. Switch from a face-to-face environment in the classroom to an online learning environment. Through social media support, teachers can vary learning to attract the attention of PAUD children. In addition to influencing network access, teachers and parents are essential components to supervise children, so they do not abuse online learning. Support from teachers and parents and access to the transformation of the digital literacy-based learning environment as a new alternative that can also improve student academic outcomes through an online learning environment.
\end{abstract}




\section{PENDAHULUAN}

Era digital yang dikelilingi oleh perubahan besar pada aspek kehidupan, mempengaruhi proses pembelajaran seperti bagaimana berhubungan satu sama lain dan dalam cara belajar, para ilmuwan dan praktisi harus memahami bagaimana mengelola perubahan yang dinamis ini (Rapanta et al., 2020; Ratheeswari, 2018), serta perubahan setting lingkungan pembelajaran dari tatap muka di kelas konvensional menjadi pertemuan virtual di kelas pembelajaran online (Iftakhar Shampa, 2016; Mishra et al., 2020). Model pembelajaran online terus meningkat popularitasnya mencoba memfasilitasi peluang pendidikan modern dan fleksibel bagi siswa (Smith \& Darvas, 2017; Yuhanna et al., 2020), serta menciptakan pengalaman belajar digital interaktif yang ditemukan di kelas virtual yang menarik dan efektif dalam pendidikan (Ratheeswari, 2018; Rowe et al., 2017). Merupakan tantangan besar untuk memberikan pengalaman belajar interaktif bagi siswa, mengingat bahwa upaya yang terkait dengan peningkatan kualitas pedagogi telah menjadi katalis utama untuk mempertimbangkan kembali pendekatan pengajaran yang ditargetkan (Bakr et al., 2018; Yafie et al., 2020). Keinginan yang besar untuk memanfaatkan teknologi dapat memberikan akses sumber belajar yang lebih mudah dan beragam dalam mengatasi masalah jarak antara siswa dan guru serta memfasilitasi peningkatan interaksi dan kolaborasi dalam kelas online (Herliandry et al., 2020; Yustika \& Iswati, 2020), menjadi alasan dasar perlunya pendidikan di kelas virtual dan penelitian mengenai aspek-aspek di dalamnya dilakukan. Kondisi saat ini pengguna Internet di Indonesia meningkat sebesar 22\%. Pada tahun 2019, 43.5\% dari 270 juta orang di Indonesia memiliki akses ke Internet. Dari sekitar 117.5 juta orang dengan akses Internet, $25.5 \%$ adalah anak-anak dan remaja (Azzahra \& Amanta 2019). Aktivitas digital juga semakin intensif, terutama di masa pandemi Covid-19. Kaum muda juga menikmati peningkatan akses ke Internet. Dalam empat tahun terakhir, persentase pelajar Indonesia berusia 5-24 tahun yang memiliki akses internet meningkat tajam dari 33.98\% menjadi 59.3\%. Sedikit lebih dari seperempat pengguna internet (25.5\%) adalah anak-anak dan remaja (Azzahra \& Amanta, 2019; Badan Pusat Statistika, 2020).

Di Indonesia, belum banyak penelitian yang mengkaji literasi digital ini. Penelitian sebelumnya lebih banyak mengkaji tentang literasi informasi, literasi media sosial dan literasi TIK pada kelompok masyarakat tertentu di beberapa daerah di Indonesia (Asok et al., 2017; Yustika \& Iswati, 2020). Salah satu sub-variabel literasi digital adalah kondisi akses internet dan penggunaan media sosial (Park, 2019). Sementara literasi digital adalah kemampuan seseorang untuk membaca dan menafsirkan data di dunia digital (Bucchi \& Saracino, 2016; Zhao et al., 2018), tingkat keterampilan yang lebih tinggi dalam mengoperasikan perangkat lunak dan perangkat keras komputer berpengaruh positif terhadap output pembelajaran yang tinggi (Bhatti et al., 2017). Ada kebutuhan mendesak untuk meningkatkan literasi digital sejak usia dini untuk meminimalkan risiko bahaya online (Unger \& Meiran, 2020), untuk membekali anakanak yang merupakan pemilih dan konsumen masa depan dengan keterampilan dan pemahaman yang mereka butuhkan untuk menjalankan peran tersebut, dan untuk memaksimalkan penggunaan internet yang bermakna (Lin et al., 2017). Pentingnya sosialisasi sebagai salah satu alternatif pendekatan untuk menumbuhkan keterampilan berpikir kritis di kelas, meningkatkan kapasitas guru baik dalam TIK dan pemikiran kritis, dan memperkenalkan keterampilan literasi digital dasar untuk orang tua (Johnson et al., 2016; Zukhairina et al., 2020).

Peran keluarga sangat penting untuk mendampingi anak dalam bersosial digital agar teknologi digital tidak disalah gunakan sehingga dapat membentuk karakter dan intelektual anak dalam pengunaan gawai (C. Y. Chen et al., 2015; Maimunah et al., 2018; Yu \& Singh, 2018). Dengan begitu proses pendampingan dalam belajar secara virtual anak akan berjalan dengan efektif dan efisien di tengah pandemi Covid-19. Penulisan artikel ini bertujuan untuk menganalisis sejauhmana kemampuan anak usia dini dalam beradaptasi dengan lingkungan pembelajaran berbasis literasi digital. Hal ini dimaksudkan bahwa kemampuan anak usia dini dalam tahap perkembangannya membutuhkan pendampingan sebagai salah satu faktor pendukung dalam proses belajarnya. Sinergi antara orang tua dan guru merupakan hal yang penting dalam pendampingan anak usia dini, sehingga dalam kondisi pandemi seperti ini pengawasn dalam pembelajaran bebasis digital pada anak usia dini dapat diarahkan dengan baik. Di mana kondisi pandemic saat ini, menekankan pada transformasi pembelajaran berbasis digital. Sehingga penerapan digital pada anak usia dini tersebut akan sangat menarik untuk diketahui informasinya.

\section{METODE}

Penelitian ini menggunakan pendekatan kualitatif deskriptif. Penelitian deskriptif berusaha menggali kompleksitas yang ada sehingga dapat dihasilkan pemahaman (Becker \& Renger, 2017). Menarik untuk mengeksplorasi literasi digital dalam isu pendidikan, informasi tersebut mengingat publikasi lebih lanjut terkait topik ini masih jarang. Penulisan paper ini merupakan jenis artikel library description yang diperoleh dari artikel ilmiah relevan terkait dengan topik. Kemudian 30 artikel yang ditemukan (tercantum 
dalam referensi) dipelajari, serta data lain didukung melalui hasil observasi dan wawancara, dan kemudian materi disajikan dan dijelaskan dalam perspektif dan kata-kata penulis. Subjek dalam penelitian ini adalah 20 anak usia dini di PAUD Annawawiyah Arrahmaniyah di daerah Jakarta Timur. Kemudian wawancara dilakukan pada empat orang tua siswa, hal ini dilakukan karena pentingnya atau keikutsertaanorang tua dalam mengawasai anaknya selama pembelajaran online. Pengambilan data dengan observasi dan wawancara, karena penelitian ini adalah kualitatif dan tidak menggunakan instrument. Sehingga pedoman observasi dan wawancara secara terbuka yang berfokus pada tiga aspek penting sebagai pedoman pengukuran, yaitu: dukungan media sosial, kondisi jaringan atau akses, dan peningkatan hasil akademik selama anak belajar online. Tiga aspek penting ini dijadikan sebagai pedoman alat ukur dalam menghimpun data dan informasi melalui observasi dan wawancara, selain itu penulis juga berperan sebagai instrumen utama sebagai informan dalam memantau dan menghimpun informasi di lapangan. Analisis data menggunakan triangualasi sumber untuk menggali pentingnya informasi yang mendalam dengan desain penelitian dari Miles dan Huberman (Aeni et al., 2020; Maimunah et al., 2018).

Proses validasi informasi, penelitian ini juga melakukan cross data check dengan dimensi terkait literasi digital dari hasil pengumpulan data yang dilakukan. Rujukan dari berbagai teori literasi sains digunakan untuk mendukung dilakukannya observasi, fokus penelitian ini adalah untuk mengulas dan mendalami literasi digital di PAUD Annawawiyah Arrahmaniyah di Jakarta Timur. Data yang dihimpun berdasarkan observasi kemudian dilakukan reduksi data dalam mengkonstruksi analisis melalui tiga inti yang terdiri dari 1) Media sosial merupakan salah satu komponen pendukung literasi digital; 2) Kondisi pengaruh akses; dan 3) Kinerja dalam pembelajaran online (Yustika \& Iswati, 2020). Berikutnya dilakukan wawancara untuk memastikan kembali data yang sebelumnya diperoleh dari hasil observasi atau melakukan member checking terhadap sumber data. Langkah terakhir dilakukan penarikan kesimpulan atas hasil temuan yang diperoleh di lapangan untuk diinterpretasikan secara keseluruhan. Pedoman wawancara sebagai kisi-kisi dalam pelaksanaan penelitian disajikan pada Tabel 1.

Tabel 1. Kisi-kisi pedoman wawancara

\begin{tabular}{|c|c|c|c|}
\hline Dimensi & Indikator & $\begin{array}{l}\text { No. Butir } \\
\text { Pertanyaan }\end{array}$ & Jumlah \\
\hline \multirow[t]{2}{*}{ Media Sosial } & 1. Kemudahan dalam mendapatkan informasi. & 1 dan 2 & 4 \\
\hline & 2. Memiliki kepercayaan terhadap sosial media. & 3 dan 4 & \\
\hline \multirow[t]{2}{*}{ Akses } & $\begin{array}{l}\text { 1. Penggunaan komputer sendiri atau ketersediaan } \\
\text { koneksi }\end{array}$ & 5 & 3 \\
\hline & 2. Akses teknologi komunikasi dan informasi siswa & 6 dan 7 & \\
\hline $\begin{array}{l}\text { Kinerja dalam } \\
\text { pembelajaran online }\end{array}$ & Siwa memiliki keterampilan dan pengetahuan baru & 8 & 1 \\
\hline Jumlah & & & 8 \\
\hline
\end{tabular}

\section{HASIL DAN PEMBAHASAN}

Hasil

Dari temuan selama penelitian di lapangan terlihat bahwa orang tua zaman milenial sudah mampu dalam mengoprasikan media digital dengan baik sehingga memudahkan orang tua dalam mendampingi anak di rumah membantu anak mengerjakan tugas yang diberikan sekolah secara online selama masa pandemi covid-19. Pentingnya penerapan literasi digital pada anak usia dini di PAUD Annawawiyah Arrahmaniyah, sesuai dengan hasil wawancara yang sudah dilakukan di masa pandemi orang tua perlu mengembangkan pengetahuan tentang digital guna mengikuti era digital di masa pandemi. Penelitian ini berpedoman pada aspek digital yang telah dilakukan oleh (Yustika \& Iswati, 2020), menunjukkan komponen literasi digital seperti akses internet, kemampuan dan keaktifan respon siswa dalam diskusi, yang kemudian komponen tersebut dieksplorasi kembali penerapannya pada anak usia dini Annawawiyah Arrahmaniyah. Sehingga, beberapa informasi data dari berbagai kajian artikel dan wawancara dapat disajikan berikut ini. Pertama media social sebagai salah satu pendukung literasi digital. Melihat fenomena jejaring sosial digital dalam satu dekade terakhir, sebagian besar merujuk pada layanan berbasis internet seperti Facebook, Instagram, Twitter, dan WhatsApp yang merupakan platform yang sering digunakan oleh masyarakat. Hasil wawancara diperolah anak memperoleh informasi pembelajaran dari youtube dan anak juga dituntut untuk berpikir kritis dalam penggunaan social media. Kedua, kondisi akses mempengaruhi literasi digital. Akses internet dari rumah versus akses dari warnet, tempat kerja, atau fasilitas sekolah sangat penting untuk memahami kondisi di mana siswa harus melakukan kegiatan belajar online mereka. Hasil wawancara diperoleh bahwa siswa merasa nyaman dan tntunya proses pembelajaran yang diikiti oleh 
anak akan dipantau oleh orang tua. Dan Ketiga, literasi digital dan performa akademik dalam pembelajaran online. Peningkatan akademik siswa adalah salah satu tujuan akhir dalam tiap pembelajaran, komdisi lingkungan pembelajaran yang saat ini dilakukan online atau virtual tidak membuat seorang pendidika menyerah untuk menyamaratakan penilaian terutama tetap mematau kemandirian siswanya. Hasil wawancara diperoleh adalah Covid-19 membawa dampak bagi keberlangsungan belajar anak dirumah menggunakan media digital.

\section{Pembahasan}

\section{Media Sosial Salah Satu Komponen Pendukung Literasi Digital}

Melihat fenomena jejaring sosial digital dalam satu dekade terakhir, sebagian besar merujuk pada layanan berbasis internet seperti Facebook, Instagram, Twitter, dan WhatsApp yang merupakan platform yang sering digunakan oleh masyarakat, oleh karena itu media sosial menjadi hal yang sangat penting sebagai bagian dari konsep literasi digital dan memiliki hubungannya dengan kinerja akademik pembelajaran online (Bliss, 2019; Zhao et al., 2018). Selain sebagai media hiburan bagi masyarakat, platform media sosial dapat mempengaruhi pembelajaran dengan cara-cara yang menarik perhatian masyarakat. Dalam penerapan literasi digital dibutuhkan pengetahuan orang tua terhadap digital. Upaya membentuk kebiasaan dalam berperilaku yang positif, maka harus didasari oleh pengetahuan (Sood \& Xiao, 2018). Hal ini berhubungan dengan faktor yang mempengaruhi pengetahuan ialah suatu informasi akan memberikan pengaruh pada pengetahuan seseorang. Jika seseorang tidak diberikan sebuah informasi yang benar, maka akan terbentuk sikap yang tidak baik pula sehingga membentuk sebuah perilaku yang kurang baik atau negatif (Hamdu, 2018). Maka Pengetahuan yang dimiliki oleh orang tua juga sangat penting dalam meningkatkan literasi digital pada anak usia dini di masa pandemic. Dengan pengetahuan orang tua tentang Covid-19, di masa pandemi ini setidaknya dapat membiasakan anak dalam mengembangkan literasi digital sehingga d membantu anak dalam mengerjakan tugas secara online, pengembangan literasi digital anak yang didapatkan oleh orang tua melalui berbagai hal tertutama orang tua banyak menemukan informasi sendiri dari media berita, youtube dan internet. Perspektif media social berhubungan positif dalam memelihara kontak sosial, serta adanya dukungan emosional yang dapat mempengaruhi siswa (Al Lily et al., 2020). Hal ini dapat diartikan bahwa dukungan psikologis dari hubungan seperti keluarga dan teman baik akan sangat penting. Dalam konteks pembelajaran online, pengguna jejaring sosial dapat memiliki lebih banyak dukungan emosional daripada non-pengguna, terutama jika mereka memiliki kepercayaan diri yang rendah.

\section{Kondisi Akses Mempengaruhi Literasi Digital}

Memiliki akses ke internet adalah syarat yang diperlukan untuk berpartisipasi dalam program pembelajaran online (Golumbic et al., 2020). Aspek seperti akses ke Internet dari rumah dan bukan dari pusat komunitas atau warnet; penggunaan komputer sendiri; atau ketersediaan koneksi broadband mewakili berbagai tingkat konektivitas yang dapat dikaitkan dengan keberhasilan akademis (J. qi Chen \& Chang, 2006), karena menyediakan berbagai tingkat fleksibilitas dalam hal waktu dan ketersediaan sumber daya komputasi dan informasi (Dionisio et al., 2013). Dapat diharapkan bahwa semakin baik kondisi akses teknologi komunikasi dan informasi siswa, semakin baik kinerja akademik mereka (Mongey \& Weinberg, 2020). Misalnya, akses internet dari rumah versus akses dari warnet, tempat kerja, atau fasilitas sekolah sangat penting untuk memahami kondisi di mana siswa harus melakukan kegiatan belajar online mereka. Siswa yang harus bolak-balik ke warnet untuk mendapatkan akses Internet secara terbatas berada pada posisi yang kurang menguntungkan dibandingkan dengan siswa yang memiliki akses Internet permanen dari rumah (Ratheeswari, 2018). Kondisi berikut untuk variabel akses diukur: Waktu penggunaan Internet (dalam tahun); frekuensi koneksi ke Internet; ketersediaan akses Internet dari rumah; akses ke komputer di rumah; jumlah komputer di rumah; akses ke televisi kabel di rumah; kepemilikan saluran telepon tetap di rumah; kepemilikan ponsel; dan jumlah televisi di rumah (Rasol et al., 2020). Pengetahuan yang dimiliki orang tualah yang dapat mempengaruhi kebiasaan baik anak terhadap pembiasaan belajar anak menggunakan digital. Karena Seorang Anak butuh dibimbing dan diberikan contoh langsung dalam melakukan pebiasaan perilaku bersosial dengan kecakapan menggunakan media digital dimasa pandemi covid-19 ini, supaya anak mampu mengontrol dalam mengoprasikan media digita dengan baik. Lingkungan keluarga yang melakukan rutinitas dan kebiasaan baik akan menjadi karakter yang baik pada anak dalam meningkatkam pembiasaan belajar dengan baik. Pembiasaan belajar yang dibentuk tiap hari akan membentuk individu anak dalam keluarga akan baik. Orang tua diharapkan menjadi contoh nyata dalam bijak bersosial media sehingga perilaku ini dapat dicontoh oleh anak-anaknya. Sehingga anak-anak akan meniru dan mengikuti perilaku kebiasaan orang tua tersebut (Kostolitz et al., n.d.; Wiegand-Grefe et al., 2019). 


\section{Literasi Digital dan Performa Akademik dalam Pembelajaran Online}

Kemampuan seorang anak di usia dini untuk berpikir kritis akan sangat dibutuhkan ketika anak nantinya berada di masyarakat untuk memecahkan masalah yang ada (Yafie et al., 2020). Diharapkan mampu mengimplementasikan teori-teori yang didapat dalam belajar terhadap permasalahan nyata yang terjadi di masyarakat (Hamdu, 2018). Salah satu tujuan pembelajaran adalah untuk mencapai prestasi yang menjadi indikator keberhasilan pembelajaran di sekolah (Efendii et al., 2020). Siswa dengan prestasi akademik yang tinggi dianggap memiliki kemampuan intelektual yang tinggi dan memiliki peluang sukses di masyarakat, baik dalam hasil pembelajaran dan kemudian bekerja secara professional (Alwi, 2017). Prestasi akademik sangat dibutuhkan oleh siswa karena dianggap mampu menggambarkan kemampuan siswa dari hasil perilaku belajar berupa perubahan positif pada diri siswa meliputi keterampilan dan pengetahuan baru (Grimminger-Seidensticker \& Möhwald, 2020). Ada beberapa faktor yang dapat mempengaruhi pencapaian prestasi akademik, antara lain faktor internal yaitu faktor fisik (kesehatan, kecacatan), psikologis (kecerdasan, sikap, bakat, minat dan motivasi), dan faktor eksternal yaitu faktor dukungan keluarga, manajemen. Lembaga pendidikan, masyarakat dan media massa, dan terakhir faktor pendekatan pembelajaran (approach learning) (Y. C. Chen, 2019).

Peningkatan akademik siswa adalah salah satu tujuan akhir dalam tiap pembelajaran, komdisi lingkungan pembelajaran yang saat ini dilakukan online atau virtual tidak membuat seorang pendidika menyerah untuk menyamaratakan penilaian terutama tetap mematau kemandirian siswanya. Peran orang tua dalam mengawasi anaknya belajar di rumah harus ditekankan untuk melek digital, tanpa disadari orang tua merasa bahwa selain peran dalam rumah tangga tetapi mampu mengawasi anaknya dalam pelaksanaan belajar online menjadi sesuatu hal yang baru. Orang tua menyadari bahwa anaknya harus memiliki kemandirian dalam belajar terutama menasehati untuk berhati-hati dalam menggunakan teknologi. Mempelajari kemandirian siswa dalam pembelajaran online, dan efikasi diri dalam menggunakan teknologi. Kemandirian diri adalah gaya kognitif yang didasarkan pada kecenderungan seseorang untuk melakukan tugas-tugas restrukturisasi kognitif. Seseorang yang mampu belajar secara mandiri dikatakan lebih berhasil daripada mereka yang bergantung pada orang lain (Roddy et al., 2017; Smith \& Darvas, 2017). Hubungan antara kemandirian siswa dalam pembelajaran online dan self-efficacy dalam menggunakan teknologi online, dan kinerja akademik mereka, yang diukur dalam poin rata-rata (Roddy et al., 2017). Studi ini menemukan bahwa siswa yang lebih mandiri di lapangan memiliki efikasi diri yang lebih tinggi menggunakan teknologi online. Dalam studi lain menemukan bahwa keterampilan komputer berhubungan positif dengan sikap belajar online (Grimminger-Seidensticker \& Möhwald, 2020).

Lingkungan pembelajaran bebasis digital merupakan kebutuhan belajar saat ini, pemanfaatan teknologi dalam bidang pendidikan menjadikan kegiatan pembelajaran akan lebih efektif dan efisien sehingga dapat menarik minat belajar anak. Digitalisasi lingkungan pembelajaran dapat dilakukan pada konteks yang langsung terhubung dalam aktifitas pembelajaran, seperti kegiatan pembelajaran berbasis website, sumber belajar digital, dan pelaksanaan ujian daring. Peran orang tua dalam menerapkan literasi digital anak usia dini pada masa pandemi covid-19 di PAUD Annawawiyah Arrahmaniyah Lubang Buaya, Jakarta Timur. Di mana orang tua sudah mulai meyadari bahwa pendampingan dan pengawasan akan sangat penting untuk dilakukan selama nakanya melaksanakan pembelajaran online. Kemampuan orang tua dalam menyaring suatu informasi literasi digital selalu diterima dengan baik dan disampaikan kembali kepada orang-orang terdekat lainnya hal ini menjadikan suatu bentuk pengembangan informasi di bidang literasi digital dan akhirnya orang tua dapat menerapkan literasi digital pada anak usia dini pada masa pandemi covid-19 di PAUD Annawaiyah Arrahmaniyah Lubang Buaya, Jakarta Timur. Sudah saatnya orang tua untuk dapat melek teknologi dan anti gagap teknologi. Penting untuk diperhatikan bahwa transformasi lingkungan pembelajaran saat ini, khususnya pada anak usia dini memperkenalkan dan memberikan pemahaman terkait pentingnya kemampuan literasi digital.

\section{SIMPULAN}

Orang tua dan guru sebagai pendidik utama mampu mengevakuasi bahwa banyak komponenkomponen penting dalam membentuk bagian dari literasi digital, akan tetapi tiga komponen penting sudah mulai dieksplorasi pada penerapan pembelajaran anak usia dini. Dimana komponen tersebut meliput: pentingnya penggunaan media social, kondisi jaringan atau akses, dan peningkatan akademik selama pembelajaran online. Dari ketiga aspek ukur tersebut, dilakukan kolaborasi dukungan teori dan hasil temuan dari wawancara bahwa secara deskriptif ketiga komponen tersebut merupakan bagian penting untuk menumbuhkan literasi digital. Penelitian ini masih sangat luas dan perlu untuk ditindaklanjuti dan ditinjau dari berbagai aspek yang dapat disesuaikan dengan kebutuhan pendidikan. Untuk penelitian berikutnya dapat dilakukan dengan pendekatan kuantitatif dengan metode yang sesuai dan analisis statistik yang memadai. 


\section{DAFTAR RUJUKAN}

Aeni, K., Widhanarto, G. P., \& Astuti, T. (2020). Strengthening character education in elementary schools: Learning technology in school culture. International Journal of Scientific and Technology Research, 9(2), 898-902.

Al Lily, A. E., Ismail, A. F., Abunasser, F. M., \& Alhajhoj Alqahtani, R. H. (2020). Distance education as a response to pandemics: Coronavirus and Arab culture. Technology in Society. https://doi.org/10.1016/j.techsoc.2020.101317.

Alwi, S. (2017). Problematika guru dalam pengembangan media pembelajaran. Itqan, 8(2), 145-167. http://ejurnal.iainlhokseumawe.ac.id/index.php/itqan/article/download/107/65/.

Asok, D., Abirami, A. M., Angeline CV, N., \& Lavanya, R. (2017). Active learning environment for achieving higher-order thinking skills in engineering education. Proceedings - 2016 IEEE 4th International Conference on MOOCs, Innovation and Technology in Education, MITE 2016, August 2020, 47-53. https://doi.org/10.1109/MITE.2016.69.

Azzahra, N. F., \& Amanta, F. (2019). Policy Brief No. 11 Promoting Digital Literacy Skill for Students through Improved School Curriculum. Center for Indonesian Policy Studies, 1(11), 14.

Badan Pusat Statistika. (2020). Statistik Indonesia 2020 Statistical Yearbook of Indonesia 2020. Statistical Yearbook of Indonesia, April, 192. https://eprints.umm.ac.id/74328/.

Bakr, A. F., El Sayad, Z. T., \& Thomas, S. M. S. (2018). Virtual reality as a tool for children's participation in kindergarten design process. Alexandria Engineering Journal, 57(4), 3851-3861. https://doi.org/10.1016/j.aej.2018.10.003.

Becker, K. L., \& Renger, R. (2017). Suggested Guidelines for Writing Reflective Case Narratives : Structure and Indicators. https://doi.org/10.1177/1098214016664025.

Bhatti, Z., Abro, A., \& Karbasi, M. (2017). Be-Educated: Multimedia Learning through 3D Animation. 1(December), 13-22. https://arxiv.org/abs/1802.06852.

Bliss, A. C. (2019). Adult Science-Based Learning. XX(X). https://doi.org/10.1177/1045159519829042.

Bucchi, M., \& Saracino, B. (2016). "Visual Science Literacy": Images and Public Understanding of Science in the Digital Age. https://doi.org/10.1177/1075547016677833.

Chen, C. Y., Kao, C. C., Hsu, H. Y., Wang, R. H., \& Hsu, S. H. (2015). The Efficacy of a Family-Based Intervention Program on Childhood Obesity: A Quasi-Experimental Design. Biological Research for Nursing, 17(5), 510-520. https://doi.org/10.1177/1099800414565815.

Chen, J. qi, \& Chang, C. (2006). Using computers in early childhood classrooms: Teachers' attitudes, skills and practices. Journal of Early Childhood Research, 4(2), 169-188. https://doi.org/10.1177/1476718X06063535.

Chen, Y. C. (2019). Using the Science Talk-Writing Heuristic to Build a New Era of Scientific Literacy. Reading Teacher, 73(1), 51-64. https://doi.org/10.1002/trtr.1808.

Dionisio, J. D. N., Burns, W. G., \& Gilbert, R. (2013). 3D virtual worlds and the metaverse: Current status and future possibilities. ACM Computing Surveys, 45(3). https://doi.org/10.1145/2480741.2480751.

Efendii, R., Jamba, I., \& Alfarissi. (2020). Media Pembelajaran Berbasis Video Animasi Untuk Pembelajaran Jarak Jauh. Jurnal Pengabdian Sriwijaya, May, 1016-1021.

Golumbic, Y. N., Fishbain, B., \& Baram-Tsabari, A. (2020). Science literacy in action: understanding scientific data presented in a citizen science platform by non-expert adults. International Journal of Science Education, Part B: Communication and Public Engagement. https://doi.org/10.1080/21548455.2020.1769877.

Grimminger-Seidensticker, E., \& Möhwald, A. (2020). Enhancing social cohesion in PE classes within an intercultural learning program: results of a quasi-experimental intervention study. Physical $\begin{array}{llll}\text { Education and Sport } & \text { 25(3), }\end{array}$ https://doi.org/10.1080/17408989.2020.1741532.

Hamdu, G. (2018). Pengembangan Lembar Kerja Siswa Berbasis Hots Berdasarkan Taksonomi Bloom Di Sekolah Dasar. PEDADIDAKTIKA: Jurnal Ilmiah Pendidikan Guru Sekolah Dasar, 5(3), 45-58. https://ejournal.upi.edu/index.php/pedadidaktika/article/view/12487.

Herliandry, L. D., Nurhasanah, Suban, M. E., \& Heru, K. (2020). Transformasi Media Pembelajaran Pada Masa Pandemi Covid-19. Jurnal Teknologi Pendidikan, 22(1), 65-70. http://journal.unj.ac.id/unj/index.php/jtp.

Iftakhar Shampa. (2016). Google classroom: What works and how? Journal of Education and Social Sciences, 3, 12-18. https://jesoc.com/wp-content/uploads/2016/03/KC3_35.pdf.

Johnson, S. K., Buckingham, M. H., Morris, S. L., Suzuki, S., Weiner, M. B., Hershberg, R. M., Fremont, E. R., Batanova, M., Aymong, C. C., Hunter, C. J., Bowers, E. P., Lerner, J. V., \& Lerner, R. M. (2016). Adolescents' Character Role Models: Exploring Who Young People Look Up to as Examples of How to $\mathrm{Be}$ a Good Person. Research in Human Development, 13(2), 126-141. 
https://doi.org/10.1080/15427609.2016.1164552.

Kostolitz, A. C., Hyman, S. M., \& Gold, S. N. (n.d.). Journal of Child Sexual Abuse How Ineffective Family Environments Can Compound Maldevelopment of Critical Thinking Skills in Childhood Abuse Survivors. December 2014, 37-41. https://doi.org/10.1080/10538712.2014.931318.

Lin, M. H., Chen, H. C., \& Liu, K. S. (2017). A study of the effects of digital learning on learning motivation and learning outcome. Eurasia Journal of Mathematics, Science and Technology Education, 13(7), 35533564. https://doi.org/10.12973/eurasia.2017.00744a.

Maimunah, Aslamiah, \& Suriansyah, A. (2018). The Integration of Sentra-Based Learning and Involvement of Family Program at Early Childhood in Developing Character Building (Multi Case at PAUD Mawaddah and PAUD Alam Berbasis Karakter Sayang Ibu Banjarmasin, Indonesia). European Journal of Education Studies, 5(7), 49-63. https://doi.org/10.5281/zenodo.1494207.

Mishra, L., Gupta, T., \& Shree, A. (2020). Online teaching-learning in higher education during lockdown period of COVID-19 pandemic. International Journal of Educational Research Open, 1, 100012. https://doi.org/10.1016/j.ijedro.2020.100012.

Mongey, S., \& Weinberg, A. (2020). Characteristics of Workers in Low Work-From-Home and High PersonalProximity Occupations. Bfi.Uchicago.Edu, March.

Park, Y. (2019). DQ Global Standards Report 2019 Common Framework for Digital Literacy, Skills and Readiness.

Rapanta, C., Botturi, L., Goodyear, P., Guàrdia, L., \& Koole, M. (2020). Online University Teaching During and After the Covid-19 Crisis: Refocusing Teacher Presence and Learning Activity. Postdigital Science and Education, 2(3), 923-945. https://doi.org/10.1007/s42438-020-00155-y.

Rasol, R., Syed Mahadi, S. L., Mohd Khalid, F. Z., Azmi, N. S., Syed Aris, S. R., \& Abdul Razak, W. R. W. (2020). Performances in English Proficiency Course with Students' Ability in Answering Higher Order Thinking Skills Questions. Environment-Behaviour Proceedings Journal, 5(SI1), 157-162. https://doi.org/10.21834/ebpj.v5isi1.2314.

Ratheeswari, K. (2018). Information Communication Technology in Education. Journal of Applied and Advanced Research, 3(S1), 45. https://doi.org/10.21839/jaar.2018.v3is1.169.

Roddy, C., Amiet, D. L., Chung, J., Holt, C., Shaw, L., McKenzie, S., Garivaldis, F., Lodge, J. M., \& Mundy, M. E. (2017). Applying Best Practice Online Learning, Teaching, and Support to Intensive Online Environments: An Integrative Review. Frontiers in Education, 2(November), 1-10. https://doi.org/10.3389/feduc.2017.00059.

Rowe, C., Watson-Ormond, R., English, L., Rubesin, H., Marshall, A., Linton, K., Amolegbe, A., Agnew-Brune, C., \& Eng, E. (2017). Evaluating Art Therapy to Heal the Effects of Trauma Among Refugee Youth: The Burma Art Therapy Program Evaluation. Health Promotion Practice, 18(1), 26-33. https://doi.org/10.1177/1524839915626413.

Smith, V., \& Darvas, J. (2017). Encouraging Student Autonomy Through Higher Order Thinking Skills. Journal of Instructional Research, 6(1), 29-34. https://doi.org/10.9743/jir.2017.5.

Sood, R., \& Xiao, H. (2018). Pulse shapes with reduced interference via optimal band-limited functions. 2006 International Waveform Diversity and Design Conference, WDD 2006 - Proceedings, 2018-Janua(2), 1-6. https://doi.org/10.1109/WDD.2006.8321485.

Tavangarian, D., Leypold, M., Nölting, K., Röser, M., \& Voigt, D. (2004). Is e-Learning the Solution for Individual Learning?. Electronic Journal of E-Learning, 2(2), 273-280. https://www.academicpublishing.org/index.php/ejel/article/view/1467.

Unger, S., \& Meiran, W. (2020). Student Attitudes Towards Online Education during the COVID-19 Viral Outbreak of 2020: Distance Learning in a Time of Social Distance. International Journal of Technology in Education and Science, 4(4), 256-266. https://doi.org/10.46328/ijtes.v4i4.107.

Wiegand-Grefe, S., Sell, M., Filter, B., \& Plass-Christl, A. (2019). Family functioning and psychological health of children with mentally ill parents. International Journal of Environmental Research and Public Health, 16(7). https://doi.org/10.3390/ijerph16071278.

Yafie, E., Nirmala, B., Kurniawaty, L., Bakri, T. S. M., Hani, A. B., \& Setyaningsih, D. (2020). Supporting cognitive development through multimedia learning and scientific approach: An experimental study in preschool. Universal Journal of Educational Research, 8(11 C), 113-123. https://doi.org/10.13189/ujer.2020.082313.

Yu, R., \& Singh, K. (2018). Teacher support, instructional practices, student motivation, and mathematics achievement in high school. Journal of Educational Research, 111(1), 81-94. https: //doi.org/10.1080/00220671.2016.1204260.

Yuhanna, I., Alexander, A., \& Kachik, A. (2020). Advantages and disadvantages of Online Learning. Journal Educational Verkenning, 1(2), 13-19. https://doi.org/10.48173/jev.v1i2.54.

Yustika, G. P., \& Iswati, S. (2020). Digital Literacy in Formal Online Education: A Short Review. Dinamika 
Pendidikan, 15(1), 66-76. https://doi.org/10.15294/dp.v15i1.23779.

Zhao, P., Kynäshlahti, H., \& Sintonen, S. (2018). A qualitative analysis of the digital literacy of arts education teachers in Chinese junior high and high schools. Journal of Librarianship and Information Science, 50(1), 77-87. https://doi.org/10.1177/0961000616658341.

Zukhairina, Wujiati, Sari, S. R., Yennizar, Zulqarnain, \& Pujiarto, P. (2020). Parenting practices of early childhood education teachers in developing early childhood communication and critical thinking skills: Case studies. Journal of Critical Reviews, 7(7), 125-132. https://doi.org/10.31838/jcr.07.07.20. 